\title{
ABSORÇÃO DE ÁGUA POR SEMENTE DE SALSA, EM DUAS TEMPERATURAS ${ }^{1}$
}

\author{
ADRIANA PAULA D'AGOSTINI CONTREIRAS RODRIGUES², VALDEMIR ANTÔNIO LAURA³, \\ KATYUCE DA SILVA CHERMOUTH ${ }^{4}$, JULIANA GADUM²
}

\begin{abstract}
RESUMO - No presente trabalho, objetivou-se estabelecer a duração da fase II da germinação de semente de salsa de diferentes cultivares e procedências, em duas temperaturas de embebição, para posterior planejamento do condicionamento osmótico. Semente de salsa, cultivares Lisa e Portuguesa, lotes 1 e 2, foi colocada para embeber em caixa gerbox com papel filtro previamente umedecido, nas temperaturas de $25^{\circ}$ e $30^{\circ} \mathrm{C}$, em germinador do tipo Mangelsdorf. Para cada tratamento, foram utilizadas quatro repetições de $1,0 \mathrm{~g}$ de semente. As avaliações foram realizadas a cada 24 horas, quando a semente era retirada do gerbox, secada criteriosamente e pesada em balança digital $(0,001 \mathrm{~g})$, até a protrusão da raiz primária de pelo menos uma semente de cada repetição dos tratamentos, quando a semente era descartada e considerada a leitura anterior. Estabeleceu-se, para cada tratamento, uma equação ( $3^{\circ}$ grau) que se ajustasse ao padrão trifásico da germinação e delimitasse o início, o final e a duração da fase II do processo germinativo. Após a derivação da equação de $3^{\circ}$ grau, determinaramse as raízes da equação derivada ( $2^{\circ}$ grau), os pontos de inflexão das curvas e a quantidade de água absorvida pela semente, até o início da fase II (primeiro ponto de inflexão da curva). A fase II da embebição de semente de salsa iniciou-se entre 59,7 e 93,3 horas. A duração da fase II da embebição foi entre 56,7 e 91,6 horas. Em semente de salsa, a interrupção do condicionamento osmótico, na temperatura de $25^{\circ} \mathrm{C}$, deve ser entre 122,5 e 148,4 horas e na temperatura de $30^{\circ} \mathrm{C}$, entre 124,9 e 184,9 horas.
\end{abstract}

Termos para indexação: Petroselinum sativum, embebição, germinação, padrão trifásico, curva de embebição.

\section{ABSORPTION OF WATER BY PARSLEY SEEDS AT TWO TEMPERATURES}

\begin{abstract}
The objective of this study was to establish the duration of phase II of seed germination of two parsley cultivars seeds with different origins, under two soaking temperatures, viewing to gather data for future planning of osmotic conditioning studies. Parsley seeds of the 'Lisa' and 'Portuguesa' cultivars from two lots were soaked in moistened filter paper under the temperatures of 25 and 30 ${ }^{\circ} \mathrm{C}$ in an incubator chamber. For each treatment, four repetitions of $1.0 \mathrm{~g}$ of seeds were used. The evaluations were made every 24 hours, when the seeds were removed from the incubator, carefully dried and weighed in a digital scale $(0.001 \mathrm{~g})$, up until the protrusion of the primary root of at least a seed of each repetition of each treatment, when the seeds were discarded and the previous reading
\end{abstract}

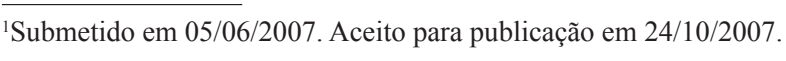

${ }^{2}$ Eng. Agrônoma, $\mathrm{Dr}^{\mathrm{a}}$. Prof ${ }^{\mathrm{a}}$. do Programa de Mestrado Profissional em Produção e Gestão Agroindustrial e do Curso de Agronomia da Universidade para o Desenvolvimento do Estado e da Região do Pantanal - UNIDERP Cx. Postal 2153 - Rua Alexandre Herculano, 1400 - Bairro Jardim Veraneio - Campo Grande, MS - CEP 79037-280 - adricontreiras@hotmail.com

${ }^{3}$ Eng. Agrônomo, Dr. Prof. do Programa de Mestrado Profissional em
Produção e Gestão Agroindustrial da Universidade para o Desenvolvimento do Estado e da Região do Pantanal - UNIDERP - valdemir.laura@gmail. com, Pesquisador da Embrapa Gado de Corte, Rodovia BR 262 km 4 Caixa Postal 154, Campo Grande, MS - CEP 79002-970 - valdemir@ cnpgc.embrapa.br

${ }^{4}$ Acadêmica do Curso de Agronomia da Universidade para o Desenvolvimento do Estado e da Região do Pantanal - UNIDERP, Campo Grande, MS. 
was considered. For each treatment, a third degree equation adjusted to the three-phase germination pattern was established viewing to delineate the beginning, the end, and the duration of phase II of the germination process. After the third degree equation was determined, the roots of the second degree equation, the points of inflexion of the curves and the amount of water absorbed by the seeds until the beginning of phase II (first point of inflexion of the curve) were calculated. Phase II of the parsley seed water absorption pattern started between 59.7 and 93.3 hours, and lasted between 56.7 and 91.6 hours. In parsley seeds, osmotic conditioning at $25^{\circ} \mathrm{C}$ should be interrupted between 122.5 and 148.4 hours, and, at $30^{\circ} \mathrm{C}$, between 124.9 and 184.9 hours.

Index Terms: Petroselinum sativum, soaking, germination, three-phase pattern, curve of absorption.

\section{INTRODUÇÃO}

A espécie Petroselinum sativum Hoffm., da família Apiaceae é originária dos países mediterrâneos, principalmente na região da Itália e da Sardenha (Gemtchújnicov, 1976). É vulgarmente conhecida como salsa ou salsinha e utilizada como condimento, sendo comercializada para consumo in natura, sozinha ou em conjunto com a cebolinha (Allium fistulosum L.) formando o condimento conhecido como cheiro verde (Heredia et al., 2003). É uma das espécies de hortaliças que não atinge sua importância pelo volume ou valor de comercialização, mas pela ampla utilização comercial como condimento.

As sementes de salsa apresentam germinação lenta, irregular e desuniforme. Para ocorrer a germinação, necessitam alcançar um nível adequado de hidratação, que permita a reativação do metabolismo e conseqüente crescimento do eixo embrionário, sendo que quanto maior a quantidade de água disponível, mais rápida será a absorção (Popinigis, 1985; Carvalho e Nakagawa, 2000).

A utilização de sementes de alta qualidade é um dos fatores mais importantes para assegurar germinação rápida, uniforme e, conseqüentemente, o estabelecimento do estande constituído por plântulas vigorosas. Um método promissor para acelerar e uniformizar o processo de germinação é o condicionamento osmótico. Os tratamentos de condicionamento osmótico se dirigem às fases I e II da embebição, durante as quais ocorre a ação de mecanismos de reparo de macromoléculas danificadas e de estruturas celulares (Bray, 1995). Durante essas fases de hidratação, os processos metabólicos das sementes necessários para a germinação, são ativados sem permitir a protrusão da raiz primária, ou seja, as sementes não atingem a fase III de embebição (Pill, 1995). A revisão das informações sobre o condicionamento osmótico permite verificar que respostas mais favoráveis ao tratamento ocorrem em espécies que produzem sementes pequenas, como hortaliças, floríferas e gramíneas forrageiras (Marcos Filho, 2005).
A reidratação é um processo físico, variando com a espécie, permeabilidade do tegumento, disponibilidade hídrica, temperatura, pressão hidrostática, área de contato semente/água, forças intermoleculares, composição química e condição fisiológica da semente (Hadas, 1982). Na embebição deve haver um gradiente de potencial hídrico e uma afinidade entre os componentes (sementes e água), como referido por Borges et al. (1994).

A embebição de água pelas sementes, sob condições ótimas, ocorre de acordo com um padrão trifásico, onde a fase I, ou embebição, é conseqüência das forças matriciais; a fase II é uma fase estacionária e é função do balanço entre o potencial osmótico e o potencial de pressão e, no início da fase III, ocorre a emissão da raiz primária (Bewley e Black, 1994). Este padrão trifásico de absorção de água foi observado em sementes de diversas espécies, como soja (McDonald-Jr. et al., 1988 e Armstrong e McDonald, 1992); Solanum elaeagnifolium Cav. (Trione e Cony, 1990); em sementes de algodão, feijão-de-corda, milho e sorgo (Prisco et al., 1992); Miconia candolleana Trian. (Borges et al., 1994) e guandu (Kalpana e Rao, 1995), sendo que a duração de cada fase variou entre as espécies. A fase estacionária praticamente não existiu ou foi muito curta em sementes escarificadas de Prosopis argentina Burk. e P. alpataco Phil. (Villagra, 1995).

O padrão trifásico nem sempre pode ser caracterizado, pois um grande intervalo entre as pesagens pode fazer com que se percam pontos de inflexão da curva de absorção que caracterizariam cada fase (Nóbrega, 1993). Fatores como água e temperatura afetam a absorção de água pelas sementes.

Devido às inúmeras pesquisas objetivando melhorar a qualidade das sementes, envolvendo tratamentos como condicionamento osmótico ou pré-hidratação, é importante o conhecimento das fases de absorção de água de diferentes espécies. Qualquer decisão crítica quanto à embebição deve ser feita enquanto as sementes permanecem na fase 
II (Bradford, 1995), como por exemplo, o encerramento do condicionamento osmótico. O estudo detalhado da curva de embebição, da duração de cada fase, dos fatores que afetam a absorção de água e do nível crítico de potencial osmótico que as sementes suportam, deve ser realizado antes de se iniciarem os experimentos envolvendo pré-condicionamento ou tratamentos de sementes.

No geral, quando as sementes endospérmicas atingem teores de água de $25 \%$ a $30 \%$ e as cotiledonares de $35 \%$ a $40 \%$, a absorção de água estabiliza ou aumenta muito pouco, começando uma fase estacionária (fase II ou fase lag), na qual vai ocorrer a digestão e o transporte ativo das substâncias de reserva. Nessa fase, os potenciais hídricos do meio e da semente ficam muito próximos e, com isso, a absorção de água pela semente se estabiliza (Taylor, 1997).

Apesar da importância, as sementes de salsa não são estudadascomrelaçãoà influência datemperaturanaembebição, não existindo informações na literatura consultada.

Portanto, no presente trabalho objetivou-se estabelecer a duração da fase II da germinação de sementes de salsa de diferentes cultivares e procedências em duas temperaturas de embebição, para posterior planejamento do condicionamento osmótico.

\section{MATERIAL E MÉTODOS}

O presente trabalho foi desenvolvido no Laboratório Didático de Análise de Sementes da Universidade para o Desenvolvimento do Estado e da Região do Pantanal UNIDERP, em Campo Grande/MS. Para a condução do experimento foram adquiridas, no comércio local, sementes de salsa (Petroselinum sativum Hoffm.) de dois lotes, das cultivares Lisa e Portuguesa, comercializados por diferentes empresas. As sementes foram colocadas para embeber em caixa gerbox com papel filtro previamente umedecido $(2,5$ vezes o seu peso), nas temperaturas de 25 e $30^{\circ} \mathrm{C}$ obtidas em germinador do tipo Mangelsdorf, sendo que a reposição da água foi feita a cada dois dias $(2,0 \mathrm{~mL}$ por gerbox). Durante a avaliação as sementes foram retiradas do gerbox e secas criteriosamente, com o auxílio de papel toalha e pesadas em balança digital com precisão de $0,001 \mathrm{~g}$.

O delineamento foi inteiramente ao acaso, em esquema fatorial 2 X 2 (duas cultivares de salsa e dois lotes) com quatro repetições de $1,0 \mathrm{~g}$ de sementes. As pesagens foram realizadas a cada 24 horas até o momento em que foi observada a protrusão da raiz primária de pelo menos uma semente de cada repetição dos tratamentos, sendo que nesse momento as sementes foram descartadas, considerando desta forma, a pesagem anterior.

Considerando que sementes em processo de germinação, durante a embebição seguem um padrão trifásico clássico (Ferreira e Borghetti, 2004), procurou-se estabelecer, para cada tratamento, uma equação de $3^{\circ}$ grau, que se ajustasse ao padrão trifásico da germinação, e delimitasse o início, o final e a duração da fase II do processo germinativo. Após a derivação da equação de $3^{\circ}$ grau, determinaram-se as raízes da equação derivada (do $2^{\circ}$ grau) e, consequentemente, os pontos de inflexão das curvas, bem como a quantidade de água absorvida pelas sementes até o início da fase II (primeiro ponto de inflexão da curva).

\section{RESULTADOS E DISCUSSÃO}

Nas Tabelas 1 e 2, encontram-se os resultados (em horas) do início, final e duração da fase II do processo de embebição de sementes de salsa, cultivares Lisa e Portuguesa, lotes 1 e 2 nas temperaturas de 25 e $30^{\circ} \mathrm{C}$, bem como a quantidade de água absorvida (mg.g $\mathrm{g}^{-1}$ de semente) até o início da fase II. Os

Tabela 1. Fase II do processo de embebição de sementes de salsa e quantidade de água absorvida (mg. $\mathrm{g}^{-1} \mathrm{de} \mathrm{semente)}^{-}$ das cultivares Lisa e Portuguesa, lotes 1 e 2 na temperatura de $25^{\circ} \mathrm{C}$.

\begin{tabular}{|c|c|c|c|c|c|}
\hline \multirow{2}{*}{ Cultivar } & \multicolumn{2}{|c|}{ Lote 1} & \multicolumn{2}{|c|}{ Lote 2} & \multirow[b]{2}{*}{$\mathrm{CV}(\%)$} \\
\hline & Portuguesa & Lisa & Portuguesa & Lisa & \\
\hline Fase II Início (h) ${ }^{\mathrm{NS}}$ & 73,0 & 64,6 & 65,0 & 70,5 & 7,35 \\
\hline Fase II Final (h) ${ }^{\mathrm{NS}}$ & 136,0 & 134,0 & 122,5 & 148,4 & 4,61 \\
\hline Duração $(\mathrm{h})^{\mathrm{NS}}$ & 63,0 & 69,5 & 57,5 & 77,8 & 7,52 \\
\hline \multirow[t]{2}{*}{ Absorção $\left(\mathrm{mg} \cdot \mathrm{g}^{-1}\right)^{*}$} & $1.607,24$ & $1.794,67$ & $1.343,45$ & $1.366,93$ & 8,61 \\
\hline & \multicolumn{2}{|c|}{$1.700,95 \mathrm{~A}$} & \multicolumn{2}{|c|}{$1.355,19 \mathrm{~B}$} & \\
\hline
\end{tabular}

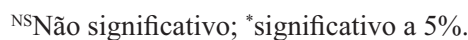


Tabela 2. Início e final da fase II do processo de embebição de sementes de salsa e quantidade de água absorvida (mg.g ${ }^{-1}$ de semente) das cultivares Lisa e Portuguesa, lotes 1 e 2 na temperatura de $30^{\circ} \mathrm{C}$.

\begin{tabular}{|c|c|c|c|c|c|}
\hline \multirow{2}{*}{ Cultivar } & \multicolumn{3}{|c|}{ Lote 1} & \multicolumn{2}{|c|}{ Lote 2} \\
\hline & Portuguesa & Lisa & Portuguesa & Lisa & $\mathrm{CV}(\%)$ \\
\hline Fase II Início (h) ${ }^{* a}$ & 93,3 & 59,7 & 66,7 & 68,3 & 15,27 \\
\hline \multirow[t]{2}{*}{ Fase II Final $(\mathrm{h})^{*}$} & 184,9 & 125,3 & 129,8 & 124,9 & 9,69 \\
\hline & \multicolumn{2}{|c|}{ Portuguesa 157,35A } & \multicolumn{2}{|c|}{ Lisa $125,1 \mathrm{~B}$} & \\
\hline Duração $(\mathrm{h})^{\mathrm{NS}}$ & 91,6 & 65,6 & 63,1 & 56,7 & 35,56 \\
\hline \multirow[t]{2}{*}{ Absorção (mg.g $\left.\mathrm{g}^{-1}\right)^{*}$} & $1.227,49$ & $1.170,24$ & $1.235,52$ & $1.184,79$ & 3,69 \\
\hline & \multicolumn{2}{|c|}{ Portuguesa 1.231,50A } & & \multicolumn{2}{|c|}{ Lisa $1.177,51 \mathrm{~B}$} \\
\hline
\end{tabular}

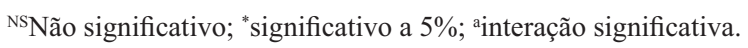

valores foram obtidos a partir da derivação das equações de $3^{\circ}$ grau (Figuras 1 e 2 ).

De um modo geral observou-se que a fase II, quando as sementes foram embebidas a temperatura de $25^{\circ} \mathrm{C}$, iniciouse entre 64,6 e 73,0 horas, tendo a duração entre 57,5 e 77,8 horas. Já para a embebição em temperatura de $30^{\circ} \mathrm{C}$, observou-se que a fase II iniciou-se entre 59,7 e 93,3 horas, com duração entre 56,7 e 91,6 horas.

O padrão trifásico foi mais evidente quando a absorção se deu na temperatura de $30^{\circ} \mathrm{C}$ (Figuras 1 e 2), confirmando a observação de Bewley e Black (1994), em condições ótimas para apresentação deste padrão.

$\mathrm{Na}$ temperatura de $30^{\circ} \mathrm{C}$, o final da fase estacionária (fase II) foi mais curto para a cultivar Lisa, independente da procedência (Tabela 2), evidenciando diferenças entre os distintos materiais genéticos.

A influência da temperatura foi mais evidente na fase I, de absorção rápida, verificando-se (numericamente) que a $25^{\circ} \mathrm{C}$, a absorção, em miligramas de água por grama de semente, foi muito maior que a $30^{\circ} \mathrm{C}$ (Tabelas 1 e 2 ).

Durante o processo germinativo a água atua como um agente estimulador e controlador, uma vez que, além de promover o amolecimento do tegumento, favorecendo a penetração do oxigênio, e aumentar o volume do embrião e dos tecidos de reserva, estimula as atividades metabólicas básicas, favorecendo o crescimento do eixo embrionário (Marcos Filho, 1986).

No processo de embebição das sementes de salsa na temperatura de $25^{\circ} \mathrm{C}$ (Figura 1) pode-se observar que o

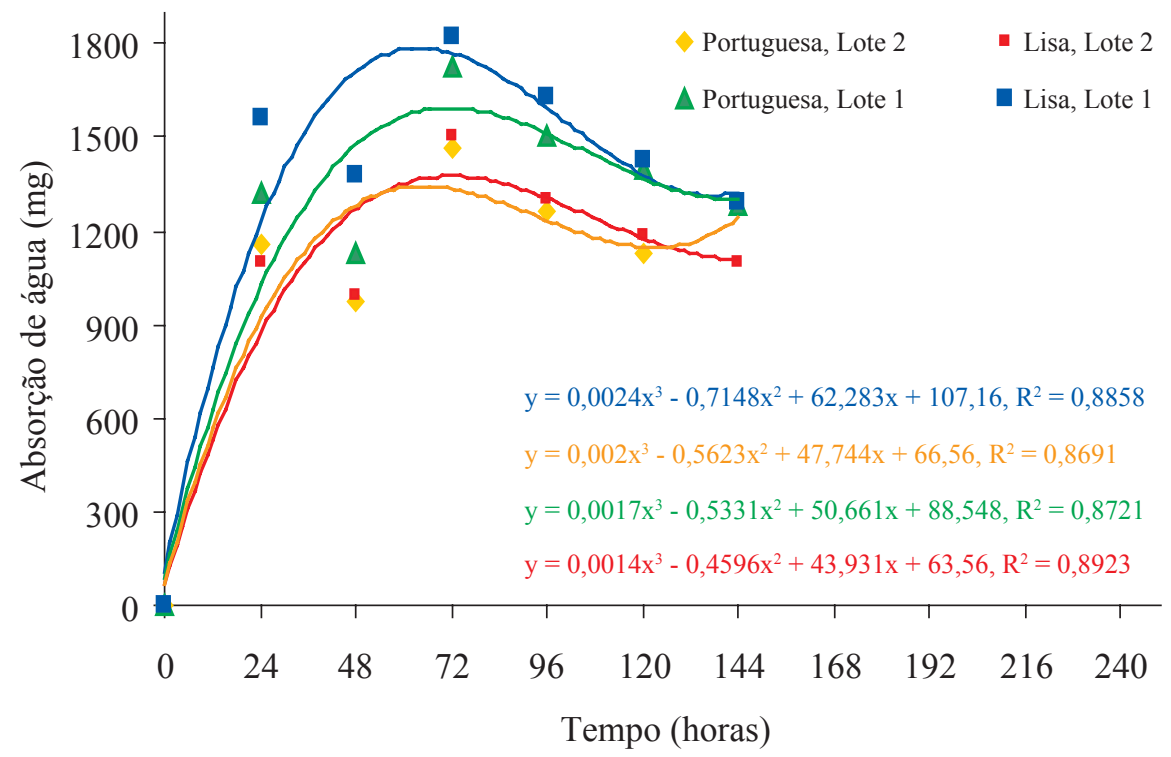

Figura 1. Absorção de água por sementes de salsa (Petroselinum sativum $\mathrm{Hoffm}$.) a $25^{\circ} \mathrm{C}$. 


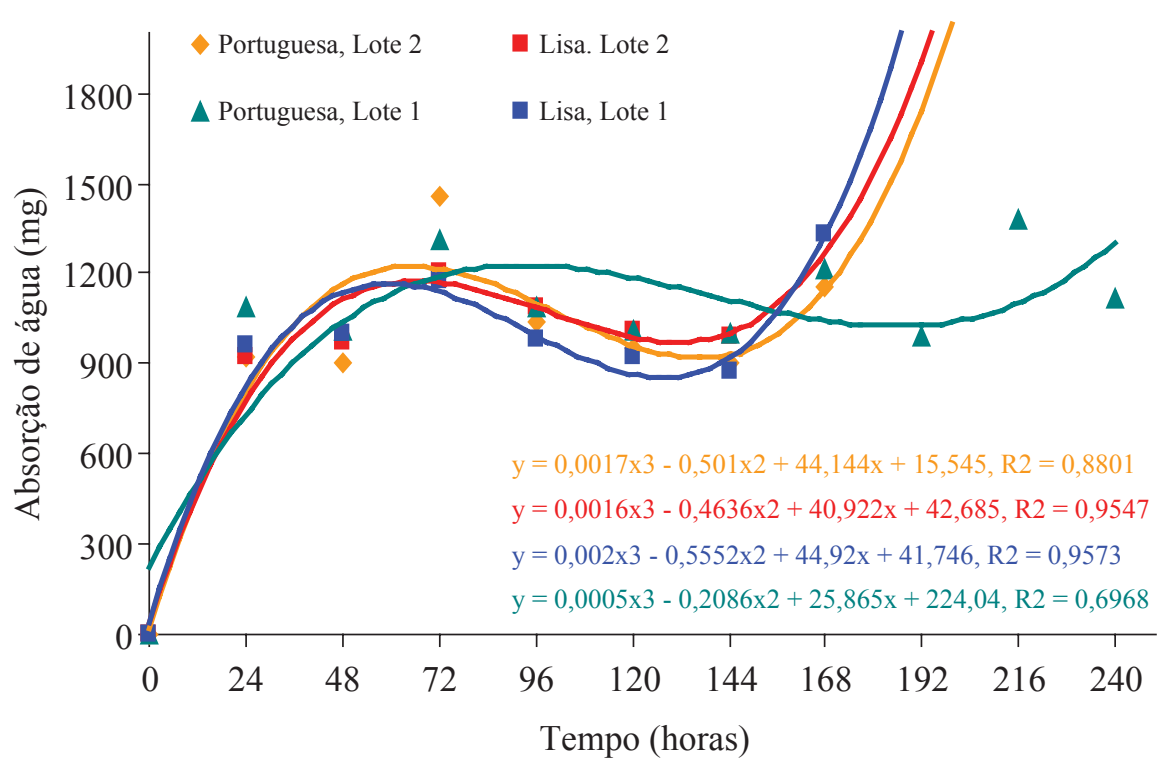

Figura 2. Absorção de água por sementes de salsa (Petroselinum sativum $\mathrm{Hoffm}$.) a $30^{\circ} \mathrm{C}$.

início da fase II para o lote 1 da cultivar Lisa ocorreu após 64,6 horas do início da embebição (Tabela 1). Para a cultivar Portuguesa lote 2, ocorreu após 65,0 horas, para Lisa lote 2, 70,5 horas e Portuguesa lote $1,73,0$ horas (Tabela 1) após o início da embebição.

A duração da fase II (Figura 1) do processo de embebição deu-se da seguinte forma: para a cultivar Portuguesa lote 2, 57,5 horas (Tabela 1), Portuguesa lote 1, 63,0 horas, Lisa lote 1, 69,5 horas e Lisa lote 2, 77,8 horas (Tabela 1). No final da fase II, a quantidade de água absorvida pelas sementes foi maior para o lote $1\left(1.700,95 \mathrm{mg} \cdot \mathrm{g}^{-1}\right)$, do que para o lote 2 $\left(1.355,19 \mathrm{mg} \cdot \mathrm{g}^{-1}\right)$, independente da cultivar (Tabela 1).

Durante o processo de embebição das sementes de salsa na temperatura de $30^{\circ} \mathrm{C}$ (Figura 2, Tabelas 2 e 3) podese observar que, para o início da fase II, houve interação significativa entre procedências e cultivares. Para a cultivar Lisa, lote 1 ocorreu após 59,7 horas (Tabela 2 e 3) do início da embebição. Para a cultivar Lisa, lote 2 ocorreu após 68,3 horas, para Portuguesa, lote 2, 66,7 horas e Portuguesa, lote 1, 93,3 horas (Tabelas 2 e 3) após o início da embebição.

A duração da fase II (Figura 2) do processo de embebição deu-se da seguinte forma: para a cultivar Lisa, lote 2, 56,7 horas, Portuguesa, lote 2, 63,1 horas, Lisa, lote 1, 65,6 horas e Portuguesa, lote 1, 91,6 horas (Tabela 2).

Pode-se observar que o início da fase II foi mais rápido para a cultivar Portuguesa, lote 2 e Lisa, lote 1 (Tabela 3). Independente da cultivar, o lote 2 iniciou a fase II da germinação mais rápido que o lote 1 .

As sementes provenientes do lote 1 , independente da
Tabela 3. Desdobramento da interação cultivar X lote para início da Fase II do processo de embebição de sementes de salsa na temperatura de $30^{\circ} \mathrm{C}$.

\begin{tabular}{lcc}
\hline & \multicolumn{2}{c}{ Lote } \\
\cline { 2 - 3 } Cultivar & 1 & 2 \\
\cline { 2 - 3 } & & $66,7 \mathrm{Ba}$ \\
Portuguesa & $93,3 \mathrm{Aa}$ & $68,3 \mathrm{Aa}$ \\
\hline
\end{tabular}

Médias seguidas pela mesma letra, maiúscula nas linhas e minúsculas nas colunas, não diferem entre si (Tukey 5\%).

cultivar, absorveram maior quantidade de água, a $25^{\circ} \mathrm{C}$, para iniciar a fase II, em comparação às sementes do lote 2 (Tabela 1). Essas diferenças, para a procedência, não foram observadas quando a embebição foi realizada a $30^{\circ} \mathrm{C}$ (Tabela 2); quando observou-se maior absorção de água para as sementes das cultivares Portuguesa $\left(1.321,50 \mathrm{mg} \cdot \mathrm{g}^{-1}\right)$ do que para as cultivares Lisa $\left(1.177,51 \mathrm{mg} \cdot \mathrm{g}^{-1}\right)$.

De maneira geral, independente da cultivar e procedência, a quantidade de água absorvida ate o início da fase II foi maior para sementes embebidas a $25^{\circ} \mathrm{C}\left(1.528 \mathrm{mg} \cdot \mathrm{g}^{-1}\right)$ do que a $30^{\circ} \mathrm{C}\left(1.204 \mathrm{mg} \cdot \mathrm{g}^{-1}\right)$.

\section{CONCLUSÕES}

A fase II da embebição de sementes de salsa inicia-se entre 59,7 e 93,3 horas. 
A fase II da embebição de sementes de salsa tem duração entre 56,7 e 91,6 horas.

Em sementes de salsa, a interrupção do condicionamento osmótico, na temperatura de $25^{\circ} \mathrm{C}$, deve ser programada para ocorrer entre 122,5 e 148,4 horas.

Em sementes de salsa, a interrupção do condicionamento osmótico, na temperatura de $30^{\circ} \mathrm{C}$, deve ser programada para ocorrer entre 124,9 e 184,9 horas.

\section{REFERÊNCIAS}

ARMSTRONG, H.; McDONALD, M.B. Effects of osmoconditioning on water uptake and electrical conductivity in soybean seeds. Seed Science \& Technology, Zürich, v.20, n.3, p.391-400, 1992.

BEWLEY, J.D.; BLACK, M. Seeds - physiology of development and germination. 2.ed. New York: Plenum Press, 1994. 445p.

BORGES, E.E.L.; SILVA, L.F.S.; BORGES, R.C.G. Avaliação do osmocondicionamento na germinação de sementes de quaresminha (Miconia candolleana Trian.). Revista Brasileira de Sementes, Brasília, v.16, n.1, p.90-94, 1994.

BRADFORD, K.J. Water relations in seed germination. In: KIGEL, J.; GALILI, G. (eds.). Seed development and germination. New York: Marcel Dekker Inc., 1995. p.351396.

BRAY,C.M., Biochemical processes during the osmopriming of seeds. In: KIGEL, J.; GALILI, G. Seed development and germination. New York: Marcel Dekker, Inc., Cap.28, p.767-789, 1995.

CARVALHO, N.M.; NAKAGAWA, J. Sementes: ciência, tecnologia e produção. 4.ed. Jaboticabal: Funep, 2000. 588p.

FERREIRA, A.G.; BORGHETTI, F. (orgs.). Germinação: do básico ao aplicado. Artmed, Porto Alegre, 2004. 323p.

GEMTCHÚJNICOV, I.D. de. Manual de Taxonomia Vegetal. Editora Agronômica Ceres, São Paulo, 1976. 368p.

HADAS, A. Seed-soil contact and germination. In: KHAN, A.A. (ed.). The physiology and biochemistry of seed development, dormancy, and germination. Armsterdam: Elsevier, 1982. p.507-527.

HEREDIA Z., N.A.; VIEIRA, M.C.; WEISMANN, M.; LOURENÇÃO, A.L.F. Produção e renda bruta de cebolinha e de salsa em cultivo solteiro e consorciado. Horticultura Brasileira, Brasília, v. 21, n. 3, p. 574-577, 2003.

KALPANA, R.; RAO, K.V.M. On the ageing mechanism in pigeonpea (Cajanus cajan (L.) Millsp.) seeds. Seed Science \& Technology, Zürich, v.23, n.1, p.1-9, 1995.

MARCOS FILHO, J. Fisiologia de Sementes de Plantas Cultivadas. Piracicaba: Fealq, v.12, 2005. p.383-427.

MARCOS FILHO, J. Germinação de sementes. In: SEMANA DE ATUALIZAÇÃO EM PRODUÇÃO DE SEMENTES, 1., Piracicaba, 1986. Trabalhos apresentados. Campinas: Fundação Cargill, 1986. p.11-39.

McDONALD-JR., M.B.; VERTUCCI, C.W.; ROOS, E.E. Soybean seed imbibition: water absorption by seed parts. Crop Science, Madison, v.28, n.6, p.993-997, 1988.

NÓBREGA, L.H.P. Estresse hídrico na germinação de sementes e no crescimento inicial de plantas de diversas cultivares de soja com determinados níveis de vigor. Jaboticabal: FCAV/UNESP, 1993. 165p. (Dissertação Mestrado).

PILL, W.A. Low water potential and presowing germination treatments to improve seed quality. In: BASRA, A.S. Seed Quality: basic mechanisms and agricultural implications. Binghamton, NY: The Haworth Press, cap.10, 1995. p.319-359.

POPINIGIS, F. Fisiologia de sementes. Brasília: AGIPLAN, 1985. 289p.

PRISCO, J.T.; HADDAD, C.R.; BASTOS, J.L.P.. Hydrationdehydration seed pre-treatment and its effects on seed germination under water stress conditions. Revista Brasileira de Botânica, São Paulo, v.15, n.1, p.31-35, 1992.

TAYLOR, A.C. Seed storage, germination and quality. In: WIEN, H.C. (Ed.) The physiological of vegetable crops. New York, 1997, p.1-36.

TRIONE, S.O.; CONY, M.A. Thermoperiodism and other physiological traits of Solanum elaeagnifolium seeds in relation to germination. Seed Science \& Technolology, Zürich, v.18, n.1, p.25-39, 1990.

VILLAGRA, P.E. Temperature effects on germination of Prosopis argentina and P. alpataco (Fabaceae: Mimosoideae). Seed Science \& Technology, Zürich, v.23, n.3, p.639-646, 1995. 